\title{
Emergency physicians should not write orders for hospital admissions
}

\author{
Paul Pageau, MD*; Robin Clouston, $\mathrm{MD}^{+}$; Jo-Ann Talbot, $\mathrm{MD}^{+}$; Paul Atkinson, MB BCh BAO, $\mathrm{MA}^{\dagger}$
}

Keywords: Admission orders, transitions in care, emergency department crowding

\section{INTRODUCTION}

\section{Paul Atkinson (@eccucourse)}

This series of editorials will provide CFEM readers with the opportunity to hear differing perspectives on topics pertinent to the practice of emergency medicine (EM). The debaters have been allocated opposing arguments on topics on which there is some controversy or perhaps scientific equipoise.

We continue with the topic of whose responsibility it is to write admission orders for patients being admitted to the hospital from the emergency department (ED). By writing admission orders, are emergency physicians reinforcing the idea that they are working "for" attendings and are not specialists in their own right? Alternatively, are they simply ensuring that patient safety is maintained pragmatically until the admitting doctor is available? Might writing orders actually promote ongoing poor behaviour by admitting physicians, who can then delay their assessment of their new patient? Or does it contribute to physician wellness by allowing on-call physicians to rest more, out of hours?

Dr. Paul Pageau, academic and clinician, as well as past president of the Canadian Association of Emergency Physicians (CAEP), makes the argument, consistent with the official CAEP position statement, that it is dangerous for emergency physicians (EP) to write admission orders for patients being admitted, with Drs. Robin
Clouston and Jo Ann Talbot, both active academics, quality experts, and clinicians, responding that it is safe and responsible for ensuring patients have their orders completed by whoever is present and willing.

Readers can follow the debate on Twitter and vote for either perspective, by going to @CJEMonline or by searching \#CJEMdebate.

$\underline{\text { FOR }}$

\section{Paul Pageau (@PageauP)}

We are not your house staff-why EPs should not write orders for hospital admissions. Imagine, for a moment, that you are a patient in the ED. You are unfortunately quite ill. You have been assessed, diagnosed, and treated for your acute illness by a competent EP. You are told that you require care in the hospital and must be admitted. Your initial anxiety has been eased by the effective, competent care in the ED. The EP, however, is now explaining that although you will be staying in the hospital, the physician taking over care will not see you until the next morning. "OK," you say anxiously, wondering who is in charge of your care.

In some institutions, this is common. In others, this never happens because the admitting physicians or a delegate attends to their patients in the ED, assesses their condition, checks the treatment plan, and writes the admission orders. Policy and best practices tell us that EPs should not write orders for hospital admissions.

CAEP has a clear policy recommending against the practice of writing admission orders. ${ }^{1}$ The American

From *University of Ottawa, Ottawa, ON; and tDalhousie University, Saint John Regional Hospital, NB.

Correspondence to: Dr. Paul Atkinson, Department of Emergency Medicine, Dalhousie University, Saint John Regional Hospital, 400 University Ave., Saint John, NB E2L 4L4; Email: paul.atkinson@dal.ca

(c) Canadian Association of Emergency Physicians

CJEM 2019:21(2):170-174

DOI 10.1017/cem.2018.489 
College of Physicians policy on Writing Admission and Transition Orders states: "best patient care occurs when there is no ambiguity as to which clinician is responsible for the care of a patient. ${ }^{2}$ The clinician in charge of a hospitalized patient's care is established when she accepts responsibility for the patient's care by verbal or written communication, by policy, or by providing, authorizing, or writing admission orders for that patient." 3 Other international EM organizations have produced similar statements. ${ }^{4,5}$

These policy statements recognize the modern-day role of an EP. Many years ago, long before Grant Innes was publishing $C F E M$ from his basement or before Ian Stiell was puzzled why every ankle was getting an $\mathrm{X}$-ray, EPs were defined by where they worked, not what they did. "Emergency rooms," if they existed at all, were staffed by interns. Every task in the ED was a delegated task. Well, EM has grown up. EPs are not delegated house staff any more.

EM is now a recognized specialty providing “... a unique set of competencies required for the timely evaluation, diagnosis, treatment and disposition of all patients with injury, illness and/or behavioral disorders requiring expeditious care, 24/7/365." The CAEP definition goes on to state that EM is "the coordination of patient care across multiple healthcare venues and providers." The Royal College has set out comprehensive competencies for EPs in Canada. While these include skills for the transition of care, they do not include inpatient care. ${ }^{7}$ It seems illogical that there is no expectation for EPs to provide ongoing inpatient care, yet there is an expectation of establishing the parameters for that ongoing care by writing admission orders.

Although EM in Canada has grown up, it has complexities arising from geography and history. We are a large country with greater than $90 \%$ of our population living in or near towns and cities larger than 10,000 people. ${ }^{8}$ However, in the remote rural corners of our country, we have family physicians providing emergency care. In these settings, many of the family physicians are simultaneously providing essential emergency care and in-patient care. Unique solutions and agreements between local physicians in smaller centres are necessary to respond to the realities of these settings. This, however, does not mean that all EPs in all EDs in Canada should be expected to write admission orders.

The simple question of whether EPs should write admission orders raises important issues regarding the scope of EM and the risks inherent in the handover of care to in-patient physicians. Handover of care is a high-risk event. ${ }^{9}$ A lack of clarity during handover can be dangerous for admitted patients. ${ }^{10}$ EPs accepting this liability and quality risk are compromising best patient care. Indeed, the only benefit they are providing is for their consultant colleagues, who, as a result, get a better night's sleep, and worse, they may be perpetuating the myth of EPs as the interns of the hospital.

Is there an efficiency argument in support of EPs to writing admission orders? The answer is no. EPs are master problem solvers who do what is necessary to get the right care for their patients at the right time-from stabilizing and initiating treatment to transferring to another facility or arranging a safe discharge plan. When EPs take the time and do the work of an admitting physician by writing admission orders, they are taking time and care away from the next patient who is waiting for emergency care. They are also enabling consultants and admitting physicians to delay initial assessments for their patients.

Prolonged ED wait times and delayed transfer to inpatient wards are epidemic in our health care system. ${ }^{11}$ This is particularly a problem in larger academic and community centres. ${ }^{11}$ If admission orders are the rate-limiting step for transfer to the ward, then the EP problem solver feels forced to write the orders to free up a bed for the next sick patient. However, this "problem" is systemic and requires much larger scale solutions directed to the dysfunction within our hospital inpatient processes.

As a patient, would you not be more reassured by an undisputed handover of your care for that illness for which you are being admitted? National, international policy, and best practices think you would be. Your new care team should be guided by the orders established by the admitting physician with the specialized skills required of inpatient care. The CAEP position statement against writing admission orders remains relevant and important for today's EP. In-patient care is not part of the practice of modern-day EM, and EPs should not be expected to write admission orders for their admitted patients.

\section{AGAINST}

\section{Robin Clouston (@RobinVictoriaC) and Jo-Ann Talbot (@sjrhem)}

We are all in this together-why it is OK for EPs to write admission orders. In a hypothetically perfect world, once 
an EP determined that a patient needed to be admitted, he or she would call the attending physician who would promptly "attend" to the ED, examine the patient, and write comprehensive admission orders. Does anyone practice in this idyllic environment? This was the expectation in the 1990s when EM organizations were writing policies that recommended against EPs writing admission orders. The American College of Emergency Physicians (ACEP) updated their policy, most recently, in 2017 to state that it is acceptable to write holding orders or transitions orders. ${ }^{3}$ The policy of CAEP was written in $1997^{1}$ and has not been revised since, leaving Canadian EPs with some cognitive dissonance between our real-world practice and the advice of our national specialty society.

The official policy of the CAEP is that writing admission orders is the responsibility of the inpatient physician. At face value, such a policy could make our lives easier-less work for the EP! However, just as we would question the motives of the specialty colleague who tells us on the phone, "It's not my job to look after that type of patient!" so, too, should we question the merit of a policy that seeks to decrease our workload, without first examining its true effect on the quality of care we give our patients.

Certainly, any admission orders written by an EP should be limited to urgent treatments, essential home medications, and nursing instructions for the next 8-12 hours until they can be reviewed by the inpatient team. $^{3}$ EP written admission orders are time-limited "holding orders" or "transition orders," and this is the safest way to view them.

Although the practice of EPs writing holding orders has not been shown to improve patient safety, it has certainly been shown to reduce the length of stay in the ED. ${ }^{12-16}$ We know from robust crowding literature that prolonged length of stay in the ED leads to poor outcomes in elderly, stroke, and critically ill patients. ${ }^{17-21}$ Treatment delays lead to increased morbidity and mortality. ${ }^{22-28}$ As writing holding orders may reduce the ED length of stay, it has the potential to improve outcomes for ED patients.

The position statement of CAEP on overcrowding suggests that, following the admission decision, there should be a median time of transfer to an inpatient bed of two hours. ${ }^{29}$ Do you know a consultant who is always able to complete a thorough assessment and write orders within this time frame? Alternatively, when the EP writes holding orders, these can be written at the point of admission decision, providing a timely care plan to the patient and a welcome relief for nursing staff, who can arrange for a ward bed. This is both patient-centred care and efficient for ED flow.

In Canada's large urban academic hospitals, it makes perfect sense for the admitting team's resident to assess the patient in the ED and write the admission orders. However, resident duty hours in Canada decreased in 2013, based on research demonstrating increased medical errors after 24 hours of call. ${ }^{30-33}$ Additionally, 75\% of EPs work in large urban non-academic, small urban, or rural centres. ${ }^{34}$ In these hospitals, without 24-hour in-house coverage, when a stable patient requires admission, it may be unreasonable to expect an on-call physician to come to the hospital for the sole purpose of writing orders. In fact, to do so may limit the daytime care such a physician can safely provide to the community because of increased fatigue-related medical errors. In such a setting, it is perfectly acceptable and a service to our colleagues to phone the on-call physician, review the case, and write holding orders.

EPs who oppose writing transition orders often cite concerns of legal liability. In an ACEP survey, ${ }^{35}$ none of the 14 respondents were aware of any litigation resulting from EPs writing transition orders, and one respondent reported that his group had 40 million patient visits over seven years without a single claim related to writing orders. ${ }^{35}$ The only related legal case reported supported the EP, indicating that the hospitalist was responsible for updating the orders. ${ }^{36}$ The ACEP survey endorsed that emergency doctors were more likely to be protected when they had written orders or documented their discussions on the chart.

Additionally, how well do EPs communicate their plans when discussing admissions? A 2010 study in which EP to hospitalist handover interactions were recorded and analyzed found that the average handover lasted one to three minutes and that the EP spoke $68 \%$ of the time. The language used in $90 \%$ of the content was information-giving, leaving little time for exploration of issues or confirmation of understanding. ${ }^{37}$ Relying on this brief transmitter-oriented conversation to safely convey the intentions for ongoing patient care can be risky and may contribute to the significant adverse events attributed to handovers identified by the Joint Commission for Transforming Health Care. ${ }^{38}$

Policies that advise against EPs writing admission orders are outdated and from an era when EPs were interns and attendings were available to manage ED 
patients quickly. Newer policies, developed in our current reality of EM specialists with full responsibility for clearly communicating disposition decisions and in the setting of widespread hospital crowding, support the writing of transition or holding orders. These orders are a written, time-limited plan that includes urgent treatments to help move the patient from the ED to the ward. There, they will be further evaluated by the admitting team who are less fatigued by interruptions and trips to the ED. This strategy reduces the length of ED stay that has the potential to improve patient outcomes. Legally, this may be more protective than trying to communicate the care plans in brief, one-sided conversations. A safer approach would be to write the holding orders and regard this process as a final review of the patient. Am I happy with my patient's clinical status? Do these orders make sense? Have I communicated the plan to the patient, family, and nurse? If seen as such, the writing of holding orders becomes a valuable tool for completion of a thorough ED assessment and a service to our patients-and should we not all be advocating for safe and complete patient assessments?

\section{REFERENCES}

1. CAEP Position Statement on the writing of patient admission orders. CAEP/ACMU Communiqué 1998; Winter 98-99:4

2. Responsibility for admitted patients, American College of Emergency Physicians Policy statement, 2014. Available at: https://www.acep.org/globalassets/new-pdfs/policy-statements/ responsibility.for.admitted.patients.pdf

3. American College of Emergency Physicians (ACEP) Policy Statement Writing Admission and Transition Orders Revised October 2017. Available at: https://www.acep.org/ patient-care/policy-statements/writing-admission-and-transitionorders/\#sm.00056n0o11943fq2w72250oce0ptu (accessed October 14, 2018).

4. Royal College of Physicians UK. Clinical responsibility for patients in the emergency department. Available at: https:// www.rcem.ac.uk/docs/College\%20Guidelines/Clinical\%20 responsibility \% 20for \% 20patients \% 20within $\% 20$ the $\% 20$ emergency\%20department\%20-\%20Nov\%202016.pdf

5. Australian College of EM- Statement on responsibility for care in emergency departments $\mathrm{S} 18$ v03. Available at: https://acem.org.au/getmedia/566c55ca-5b0f-47d5-adc3-458 9975ac196/S18-Statement-on-responsibility-for-care-in-EDsMar-12-v03.aspx

6. McEwen J, Borreman S, Caudle J, et al. Position statement on emergency medicine definitions from the Canadian Association of Emergency Physicians. CFEM 2018;20(4):501-6.

7. The Entrustable Professional Activities of Emergency Medicine, Ottawa: The Royal College of Physicians and Surgeons of Canada; 2017.
8. Statistics Canada Rural and Small Town Canada Analysis Bulletin. Vol 8, No 3, January 2010. Available at: https:// www150.statcan.gc.ca/n1/pub/21-006-x/21-006-x2008003eng.htm

9. Kitch BT, Cooper JB, Zapol WM, et al. Handoffs causing patient harm: a survey of medical and surgical house staff. 7t Comm 7 Qual Patient Saf 2008;34(10):563-70.

10. Smith CJ, Britigan DH, Lyden E, et al. Interunit handoffs from emergency department to inpatient care: A crosssectional survey of physicians at a university medical center. 7 Hosp Med 2015;10(11):711-7.

11. CIHI data. Available at: https://www.cihi.ca/en/emergencydepartment-wait-times-in-canada-continuing-to-rise

12. Patterson J, Dutterer L, Rutt M, et al. Bridging orders and a dedicated admission nurse decreases emergency department turnaround times while increasing patient satisfaction. Ann Emerg Med 2007;50(3):351-2.

13. Amarasingham R, Swanson TS, Treichler DB, Amarasingham SN, Reed WG. A rapid admission protocol to reduce emergency department boarding times. Qual Saf Health Care 2010;19(3):200-4.

14. Emergency Department Physician Admission Holding Orders. Maine Medical Center 2013. Available at: https://smhs.gwu. edu/urgentmatters/sites/urgentmatters/files/PhysicianAdmission HoldingOrders.MaineMedicalCenter.pdf (accessed September 12, 2018).

15. Haydar SA, Strout TD, Michael R, Baumann MR. Sustainable mechanism to reduce emergency department length of stay: the use of ed holding (ed transition). orders to reduce ed length of stay. Acad Emerg Med 2016;23: 776-85.

16. Traub SJ, Temkit M, Saghafian S. Emergency department holding orders. 7 Emerg Med 2017;52(6):885-93.

17. Stolte E, Iwanow R, Hall C. Capacity-related interfacility patient transports: patients affected, wait times involved and associated morbidity. CFEM 2006;8(4):262-8.

18. Chalfin DB, Trzeciak S, Likourezos A, et al. Impact of delayed transfer of critically ill patients from the emergency department to the intensive care unit. Crit Care Med 2007; 35(6):1477-83.

19. Ackroyd-Stolarz S, Read Guernsey J, Mackinnon NJ, Kovacs G. The association between a prolonged stay in the emergency department and adverse events in older patients admitted to hospital: a retrospective cohort study. BMF Qual Saf 2011;20(7):564-9.

20. Jo S, Jeong T, Jin YH, et al. ED crowding is associated with inpatient mortality among critically ill patients admitted via the ED: post hoc analysis from a retrospective study. $A m \mathcal{F}$ Emerg Med 2015;33(12):1725-31.

21. Akhtar N, Kamran S, Singh R, et al. Prolonged stay of stroke patients in the emergency department may lead to an increased risk of complications, poor recovery, and increased mortality. 7 Stroke Cerebrovasc Dis 2016;25(3):672-8.

22. Schull MJ, Vermeulen M, Slaughter G, Morrison L, Daly P. Emergency department crowding and thrombolysis delays in acute myocardial infarction. Ann Emerg Med 2004;44(6): $577-85$.

23. Diercks DB, Roe MT, Chen AY, et al. Prolonged emergency department stays of non-ST-segment-elevation myocardial 
infarction patients are associated with worse adherence to the American College of Cardiology/American Heart Association guidelines for management and increased adverse events. Ann Emerg Med 2007;50(5):489-96.

24. Fee C, Weber EJ, Maak CA, Bacchetti P. Effect of emergency department crowding on time to antibiotics in patients admitted with community-acquired pneumonia. Ann Emerg Med 2007;50(5):501-9.

25. Pines JM, Localio AR, Hollander JE, et al. The impact of emergency department crowding measures on time to antibiotics for patients with community-acquired pneumonia. Ann Emerg Med 2007;50(5):510-6.

26. Kennebeck SS, Timm NL, Kurowski EM, Byczkowski TL, Reeves SD. The association of emergency department crowding and time to antibiotics in febrile neonates. Acad Emerg Med 2011;18(12):1380-5.

27. Pines JM, Hollander JE. Emergency department crowding is associated with poor care for patients with severe pain. Ann Emerg Med 2008;51(1):1-5.

28. Sills MR, Fairclough DL, Ranade D, Mitchell MS, Kahn MG. Emergency department crowding is associated with decreased quality of analgesia delivery for children with pain related to acute, isolated, long-bone fractures. Acad Emerg Med 2011;18(12):1330-8.

29. Affleck A, Parks P, Drummond A, Rowe BH, Ovens HJ. Emergency department overcrowding and access block. CFEM 2013;15(6):359-84.

30. Ulmer C, Miller Wolman D, Johns MM, et al. Resident Duty Hours: Enhancing Sleep, Supervision, and Safety. Institute of Medicine (US) Committee on Optimizing Graduate Medical Trainee (Resident) Hours and Work Schedule to Improve
Patient Safety. Washington (DC). US: National Academies Press; 2009.

31. Jagsi R, Kitch BT, Weinstein DF, et al. Residents report on adverse events and their causes. Arch Intern Med 2005;165 (22):2607-13.

32. Landrigan CP, Rothschild JM, Cronin JW, et al. Effect of reducing interns' work hours on serious medical errors in intensive care units. N Engl 7 Med 2004;351(18):1838-48.

33. Eastridge BJ, Hamilton EC, O'Keefe GE, et al. Effect of sleep deprivation on the performance of simulated laparoscopic surgical skill. Am 7 Surg 2003;186(2):169-74.

34. Emergency Medicine Training \& Practice in Canada. CAEP 2016. Available at: https://caep.ca/wp-content/uploads/2017/ 07/cwg0001_cwg-em_report_-_executive_summary_-_english_-_ singles_-_web1.pdf (accessed September 29, 2018).

35. ACEP policy resource and education paper (PREM). Writing Admission and Transition Orders. Available at: EMPCPREPWRITINGADM.ANDTRANS.ORDERS_1262017 FINAL.PDF (accessed September 14, 2018).

36. Unique legal risks posed by ED "Bridge Orders". Available at: https://www.reliasmedia.com/articles/135699-uniquelegal-risks-posed-by-ed-bridge-orders (accessed September 14, 2018).

37. Apker J, Mallak LA, Applegate 3rd EB, Gibson SC, Ham JJ, Johnson NA, et al. Exploring emergency physician-hospitalist handoff interactions: development of the Handoff Communication Assessment. Ann Emerg Med 2010;55(2):161-70.

38. Sentinel Event Alert 58: Hand off Communications. Joint Commission Center for Transforming Health Care. Sep 12, 2017. Available at: www.jointcommision.org (accessed September 24, 2018). 